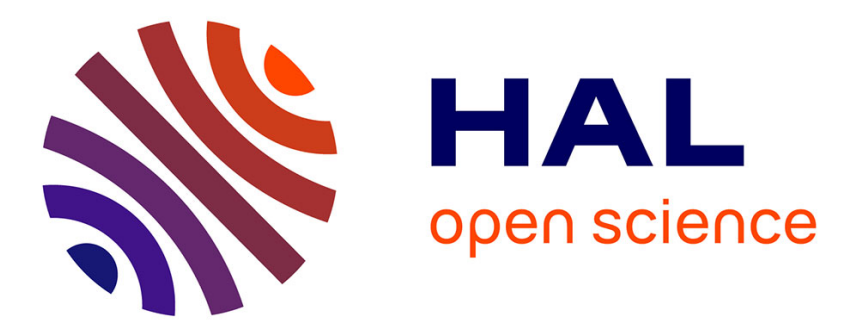

\title{
Integration of high resolution spatial and spectral data acquisition systems to provide complementary datasets for cultural heritage applications
}

Camille Chane Simon, Uwe Huxhagen, Alamin Mansouri, Adrian Heritage, Frank Boochs, Franck S. Marzani

\section{To cite this version:}

Camille Chane Simon, Uwe Huxhagen, Alamin Mansouri, Adrian Heritage, Frank Boochs, et al.. Integration of high resolution spatial and spectral data acquisition systems to provide complementary datasets for cultural heritage applications. IS\&T/SPIE Electronic Imaging meeting, Jan 2010, San Jose, United States. pp.75310L-1, 75310L-9. hal-00638588

\section{HAL Id: hal-00638588 https://hal.science/hal-00638588}

Submitted on 6 Nov 2011

HAL is a multi-disciplinary open access archive for the deposit and dissemination of scientific research documents, whether they are published or not. The documents may come from teaching and research institutions in France or abroad, or from public or private research centers.
L'archive ouverte pluridisciplinaire HAL, est destinée au dépôt et à la diffusion de documents scientifiques de niveau recherche, publiés ou non, émanant des établissements d'enseignement et de recherche français ou étrangers, des laboratoires publics ou privés. 


\title{
Integration of high-resolution spatial and spectral data acquisition systems to provide complementary datasets for cultural heritage applications
}

\author{
Camille Simon $^{\mathrm{a}, \mathrm{b}}$, Uwe Huxhagen ${ }^{\mathrm{b}}$, Alamin Mansouri ${ }^{\mathrm{c}}$, Adrian Heritage ${ }^{\mathrm{d}}$, Frank Boochs ${ }^{\mathrm{b}}$, \\ Franck S. Marzani ${ }^{\mathrm{a}}$ \\ ${ }^{a}$ Le2i, Université de Bourgogne, Bâtiment Mirande, UFR Sc. \& Tech, \\ BP 47870 - 21078 Dijon Cedex, France \\ bi3mainz, Mainz University of Applied Sciences, Lucy-Hillebrand Strasse 2, \\ 55128 Mainz, Germany \\ ${ }^{c}$ Le2i, Université de Bourgogne, Route des plaines de l'Yonne, BP 16, 89010 Auxerre Cedex, France \\ ${ }^{\mathrm{d} C}$ Cologne Institute of Conservation Science, Cologne University of Applied Sciences, Ubierring 40, \\ 50678 Cologne, Germany
}

\begin{abstract}
Modern optical measuring systems are able to record objects with high spatial and spectral precision. The acquisition of spatial data is possible with resolutions of a few hundredths of a millimeter using active projection-based camera systems, while spectral data can be obtained using filter-based multispectral camera systems that can capture surface spectral reflectance with high spatial resolution. We present a methodology for combining data from these two discrete optical measuring systems by registering their individual measurements into a common geometrical frame. Furthermore, the potential for its application as a tool for the non-invasive monitoring of paintings and polychromy is evaluated. The integration of time-referenced spatial and spectral datasets is beneficial to record and monitor cultural heritage. This enables the type and extent of surface and colorimetric change to be precisely characterized and quantified over time. Together, these could facilitate the study of deterioration mechanisms or the efficacy of conservation treatments by measuring the rate, type, and amount of change over time. An interdisciplinary team of imaging scientists and art scholars was assembled to undertake a trial program of repeated data acquisitions of several valuable historic surfaces of cultural heritage objects. The preliminary results are presented and discussed.
\end{abstract}

Keywords: laser scanning, multispectral acquisitions, cultural heritage, data fusion, image registration, stone conservation, photogrammetry, surface analysis, high resolution 3D data.

\section{INTRODUCTION}

Whilst cultural heritage objects are valued for their rarity and significance, as physical objects they are often fragile, susceptible to deterioration, and exposed to uncontrolled environments. The resulting deterioration mechanisms are wide ranging and varied (examples are microbiological growth and soluble salts), and can result in alteration or material loss of an object over time. In the case of free-standing objects or those located within historic structures - where museum storage conditions cannot be maintained - the rate of environmental deterioration can be both trenchant and expeditious. Therefore, to record and monitor the aesthetic and material attributes of cultural heritage objects in non-museum environments one requires a flexible, portable imaging system that combines non-invasive analysis and documentation techniques such as 3D modeling and multispectral imaging. By rescanning the same object over a period of time we can measure both topographic and colorimetric changes. The study of dynamic processes is of vital importance in conservation since it can provide critical information for the characterization and potential control of deterioration mechanisms, and improvement of conservation treatment methodologies ${ }^{1}$.

3D models of cultural heritage artifacts enable users to observe the object by interacting with the virtual model, without the necessity to touch the physical object. This can be useful in pedagogical settings, enabling museum visitors to 
observe the items in ways they physically could not, looking at details they cannot approach for example the head of a 5 $m$ high statue ${ }^{2}$. Digital models can also be used by archeological scholars to find the correct fit for fragments of an ancient object; there have been some attempts at developing computer algorithms to guide this process ${ }^{3}$. 3D models can also be used as a snapshot of the shape of the object at a given instant.

The need for multispectral acquisitions of cultural heritage objects stems from the requirement of high color fidelity when reproducing works of art $^{4}$. Currently the highest interest seems to be on the spectral analysis of materials for pigment identification. Though sample analysis is a reliable method to perform material identification, multispectral acquisitions may help reduce the number of samples to be taken from an object ${ }^{5}$.

There has been a significant amount of interest in utilizing spectral analysis of materials for the purposes of pigment identification. Spectral acquisitions of the same object taken at different times can be used to measure pollutant deposition, microbiological growth or pigment deterioration. Computer algorithms can also analyze spectral data to study palimpsests by revealing overwritten texts in manuscripts ${ }^{6}$. While high fidelity color reproduction only requires acquisitions in the visible range, for applications that aim at object analysis, we are interested in broader spectral ranges covering the IR and UV fluorescence, as is the case of the device describe in Ref. 5.

It is of increasing interest to integrate 3D scanning and multispectral acquisitions as they provide complementary information and their combination offers new possibilities for the analysis of cultural heritage objects. Efforts have been made to develop a single system for both color and $3 \mathrm{D}$ acquisitions ${ }^{7,8}$. In this case the color data is mostly used as texture for the 3D model.

Our own attempt at developing a multispectral 3D scanner resulted in a device with low spatial resolution ${ }^{8}$. As our goal is to perform both precise multispectral and 3D acquisitions we now use different tools for the 3D acquisition and the multispectral acquisitions. This provides us with high quality datasets. This setup is also more flexible since the optimal 3D scanner and multispectral camera for a specific application can be chosen independently. In practice we use commercially available scanners for the 3D acquisitions, and lab-built cameras capture the multispectral data. These acquisition systems are described in section 2 .
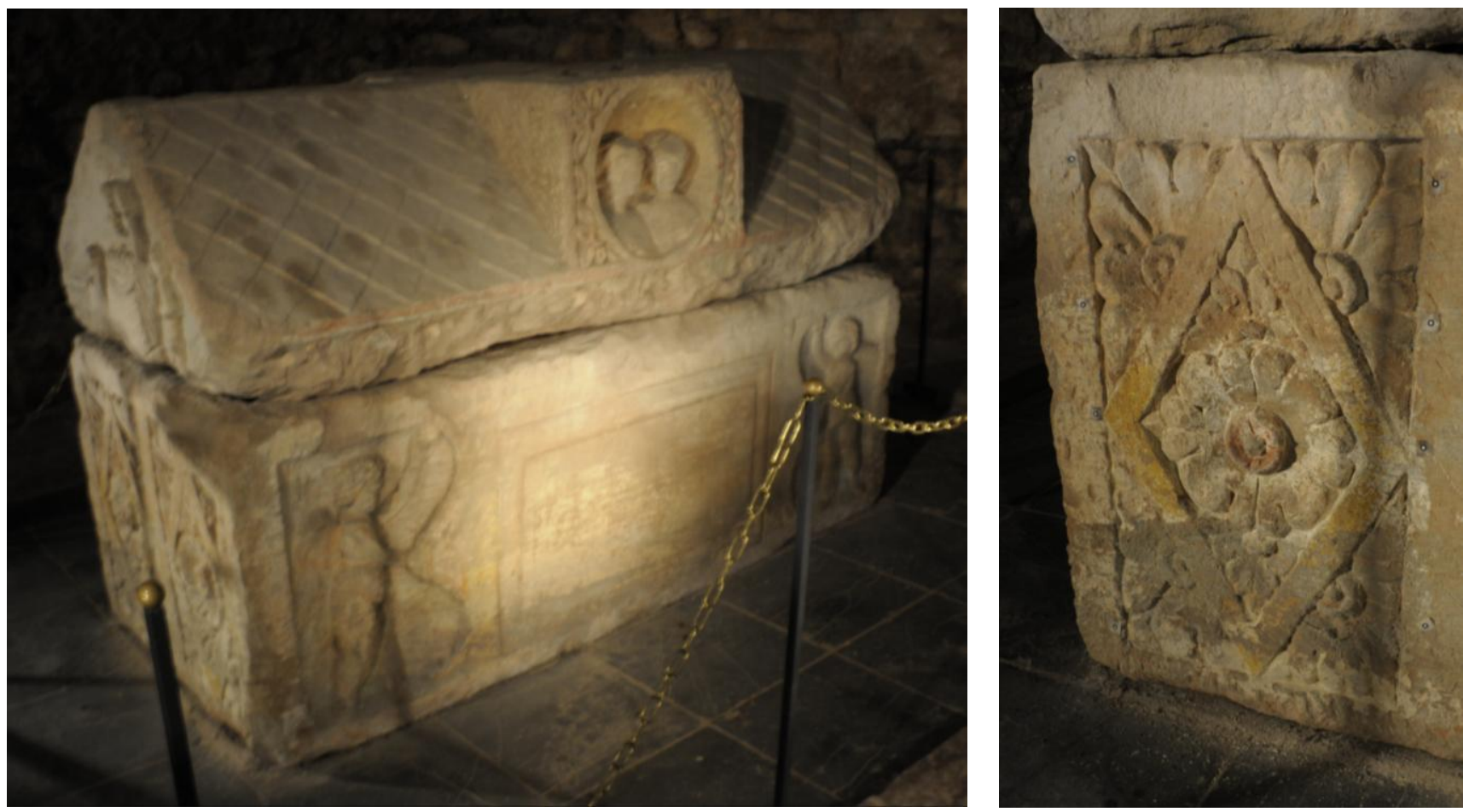

Figure 1: (a) The sarcophagus in its subterranean environment. The area selected for monitoring can be seen on the far left and in (b). Notice the traces of polychromy in the central region of the bas relief. The debris at the foot of the sarcophagus is material that has fallen from the object 
Table 1: Characteristics of the fringe projection acquisitions

\begin{tabular}{|c|c|c|c|c|c|}
\cline { 2 - 6 } \multicolumn{1}{c|}{} & Acquisition time & Scanner & $\begin{array}{c}\text { Number of points } \\
\text { per scan }\end{array}$ & $\begin{array}{c}\text { Field of view } \\
\left(\mathrm{mm}^{2}\right)\end{array}$ & $\begin{array}{c}\text { Resolution } \\
(\mathrm{mm})\end{array}$ \\
\hline $\begin{array}{c}\text { Rudesheim wall } \\
\text { painting }\end{array}$ & October 2008 & GOM Athos II & 1400000 & $200 \times 300$ & 0.25 \\
\hline $\begin{array}{c}\text { Trier Sarcopahgus: } \\
\text { base model }\end{array}$ & $\begin{array}{c}\text { December 2008 } \\
\text { December 2009 }\end{array}$ & GOM Athos III & 4000000 & $500 \times 500$ & 0.25 \\
\hline $\begin{array}{c}\text { Trier Sarcophagus: } \\
\text { details }\end{array}$ & December 2008 & GOM Athos III & 4000000 & $150 \times 150$ & 0.07 \\
\hline
\end{tabular}

This is the continuity of our work assessing how powerful optical acquisition techniques can be for the documentation of cultural heritage objects ${ }^{9}$, trying to correlate visible defects and spatial deformations. We present two applications in the field o stone conservation, combining $3 \mathrm{D}$ and multispectral acquisition techniques to monitor the aging of wall paintings in Rudesheim, Germany and of a polychrome sandstone sarcophagus in Trier, Germany.

The $16^{\text {th }}$ century wall paintings are located in the Brömser Hof in Rudesheim in a small castle which still belongs to the Brömser family and currently houses a regional museum. These wall paintings, which have been recently conserved, decorate the chambers of the Brömser Hof tower, as well as the adjacent Ahnensaal (ancester hall). Our goal is to monitor changes in these wall paintings and to detect any differences in the alteration of the restored and unrestored surfaces.

A further project aims to assess the rate of deterioration of a polychrome sandstone sarcophagus from the late $3^{\text {rd }}$ century A.D in the crypt under the Friedhofs Chapel, St. Matthias Abbey, Trier. The sarcophagus was discovered by archeologists about fifty years ago. Unfortunately, the microclimate is uncontrolled and the fluctuating relative humidity and air flow through the crypt is damaging the stone and its fragmentary remains of polychomy. This is particularly the case on the area of the sarcophagus facing the entrance the chamber. This side of the sarcophagus is the most subject to erosion as air enters from the stairway and flows out through openings over the sarcophagus. Traces of polychromy on the surface of the sarcophagus are flaking while the stone itself erodes. We want to precisely localize and measure the degradation of the sandstone and of the polychromy in this area (Figure 1).

Since we use several acquisition tools with different resolutions and different data representation, a main task is to combine data from the different sources in a common frame were they can fully complement each other while retaining their original resolution.

\section{MATERIALS AND METHODS}

\subsection{D scanning}

In both applications close range digital photogrammetry was used to acquire a common coordinate system for the subsequent 3D scans. The coordinate system of the object is defined by reference points that are represented by coded and uncoded targets. The targets are applied to the surface of the objects with an adhesive resin which does not affect the object surface and is appropriate for cultural heritage applications. These targets were positioned before the first acquisition and have remained in place since as markers to guide the registration process. Photogrammetry also provides us with color images to use as a coarse texture for the 3D models, useful for visualization purposes.

Selected surfaces of interest were digitized with GOM Atos fringe projection scanners. This system is composed of a projector and two cameras. The projector successively displays various patterns on the object to be digitized, while these projections are captured by the two cameras. The precise $3 \mathrm{D}$ coordinates of each pixel of the scanned surface can be calculated by triangulation, as long as this pixel is part of the field of view of all three optical systems. By adapting the settings and lens of the scanner we have access to a variety of scanning volumes with corresponding resolution. Our goal is to measure very subtle differences related to the wear and aging of the objects. The successive states of the object must 
Table 2: Characteristics of our multispectral cameras. We also detail the characteristics of the fixed lens of the first camera.

\begin{tabular}{|c|c|c|c|c|c|c|c|}
\cline { 2 - 7 } \multicolumn{1}{c|}{} & $\begin{array}{c}\text { Number of } \\
\text { spectral bands }\end{array}$ & $\begin{array}{c}\text { Range } \\
(\mathrm{nm})\end{array}$ & $\begin{array}{c}\text { Image size } \\
\left(\mathrm{pixel}^{2}\right)\end{array}$ & $\begin{array}{c}\text { Field of view } \\
\left(\mathrm{cm}^{2}\right)\end{array}$ & $\begin{array}{c}\text { Pixel size } \\
(\mu \mathrm{m})\end{array}$ & $\begin{array}{c}\text { Depth of field } \\
(\mathrm{mm})\end{array}$ & $\begin{array}{c}\text { Focal length } \\
(\mathrm{cm})\end{array}$ \\
\hline Fixed lens camera & 8 & $430-850$ & $1280 \times 960$ & $2.85 \times 2.2$ & 5 & 3 & 9 \\
\hline Contact less camera & 7 & $380-780$ & $1280 \times 960$ & \multicolumn{4}{|c}{} \\
\cline { 1 - 8 }
\end{tabular}

thus be finely documented. For this we use the settings which yield the most precise results and we are constrained to the smallest field of view.

In October 2008 we scanned the wall paintings in Rudesheim with a GOM Athos II scanner. For the acquisitions of the Trier sarcophagus in December 2008 and 2009 we used a more precise model, the Athos III, which we did not posses in October 2008. The settings of these successive acquisitions are detailed in Table 1.

In December 2009 we also took panoramic images of the inside of the crypt and performed 3D laser scanning of the crypt using a Faro Photon laser scanner. These acquisitions will be used for visualization purposes to enable the full 3D reconstruction of the sarcophagus and its' environment to be visualized in a virtual reality setup, for example on a stereoprojection wall.

\subsection{Multi spectral acquisitions}

Our lab-developed multispectral cameras are each composed of a monochromatic CCD camera, standard photographic lens and a set of interference filters. The filters are positioned on a motorized rotating wheel which is software controlled. One camera acquires 7 images in the $380-780 \mathrm{~nm}$ range, with the wheel and filters located in front of the camera and lens system. A more recent model is based on the same setup with a higher spatial resolution and 8 spectral

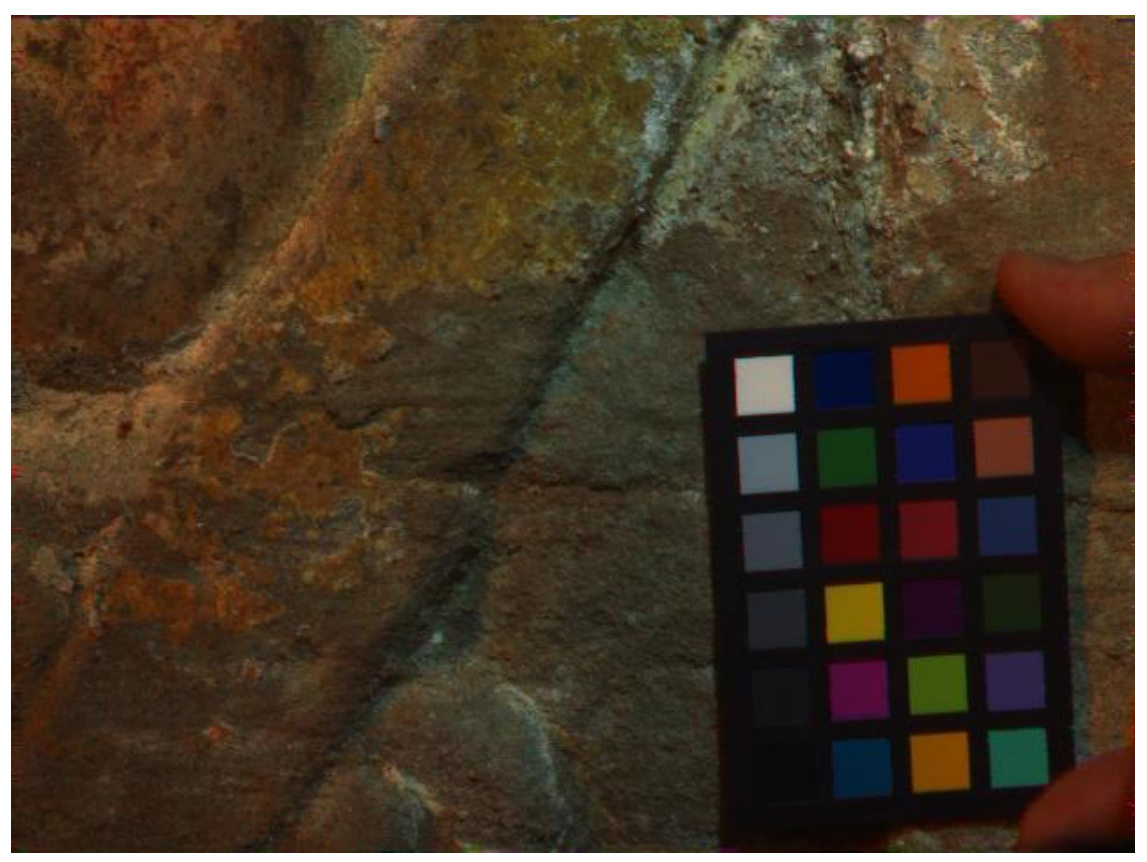

Figure 2: Color image reconstructed from multispectral acquisitions of a detail of the sarcophagus.

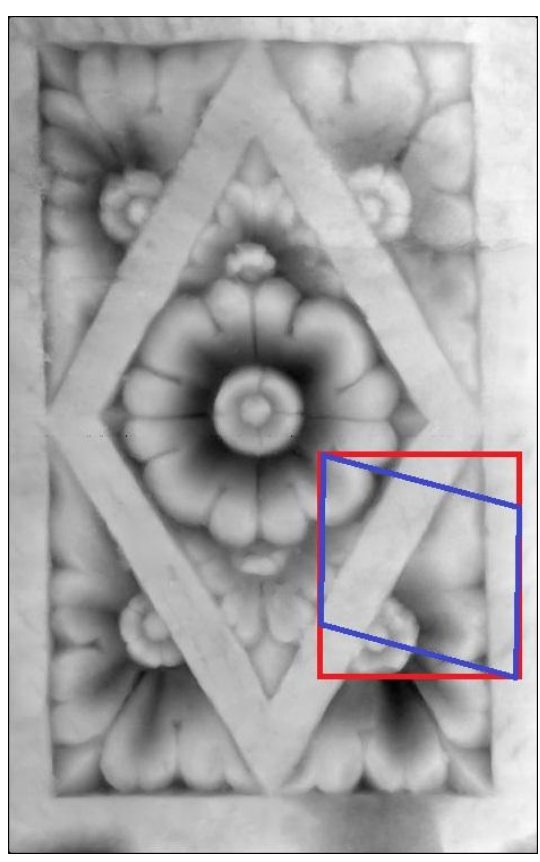

Figure 3: Digital elevation map of the sarcophagus The rectangle indicates the approximate position of Figure 2 while the blue quadrangle represents in the affine transform necessary to correctly map Figure 2 on the DEM. 
acquisitions in the 430-850 nm range. Two more spectral bands, centered at 910 and $970 \mathrm{~nm}$, can be acquired, but we do not use them as the CCD does not yield precise results in the IR spectrum. This camera model is less cumbersome than the previous one and easier to manipulate thanks to an external acquisition arm that is linked to the wheel and filters via an optical cable. In this configuration we filter the light that is emitted on the object, whereas the previous version filters the light received by the CCD. This camera has a fixed focal plane and should be used in contact with the object. The older camera, on the other hand, is a non contact spectral camera. The lens type is adapted to suit the specific requirements of the area to be imaged. We usually place the camera around $50-100 \mathrm{~cm}$ from the object and capture an area of about $20 \times 15 \mathrm{~cm}$. The characteristics of both spectral cameras are detailed in Table 2 .

The acquisition of these multispectral images is only a first step in obtaining spectral data. We feed these images to a neural-network algorithm and obtain a hyper spectral cube. Typically, we choose output plans with a $10 \mathrm{~nm}$ wavebands but a spectral resolution of $5 \mathrm{~nm}$ has also been validated ${ }^{10}$.

A Macbeth color checker is used to teach the neural network algorithms. In the case of the contact-less camera, the chart is included in each acquisition to compensate for illumination conditions. On the other hand the fixed-lens camera is used in contact with the object, shielding the surrounding light. In this case neural network teaching can be done at a different time and doesn't have to be repeated each acquisition.

Multispectral images were acquired in February 2009 using both cameras. In Rudesheim, some of the areas of interest could only be scanned with the fixed-lens camera because of the bulk of the previous system.

\subsection{Registration}

The various 3D data sets were fused together on a common geometrical coordinate system provided by the digital photogrammetry acquisitions. This is a common procedure in handling $3 \mathrm{D}$ data and has been described previously ${ }^{11}$. The registration of two 3D models of the same object taken at different times is also a straightforward task, especially when we can use the photogrametric targets to guide this process. The scans should overlap neatly since they present only minimal differences.

Once we have created a detailed digital model of the model we want to precisely assign the multispectral data to the surface of this object. However, we do not know the relative orientation of the sensors, nor do we know their exterior orientation. Furthermore we want to merge datasets with different resolutions different object representation. As we do not know the interior camera geometry this is not a common photogrammetric task and quite a challenge.

As a preliminary framework, we developed a Matlab application to combine hyperspectral data provided by the neural network algorithm with 3D data in the form of a digital elevation model (DEM). In this case the DEM is a raster storing elevation numbers. For visualization purposes an affine transform maps the highest point to a pixel value of 255 , while 0 represents the lowest elevation point.

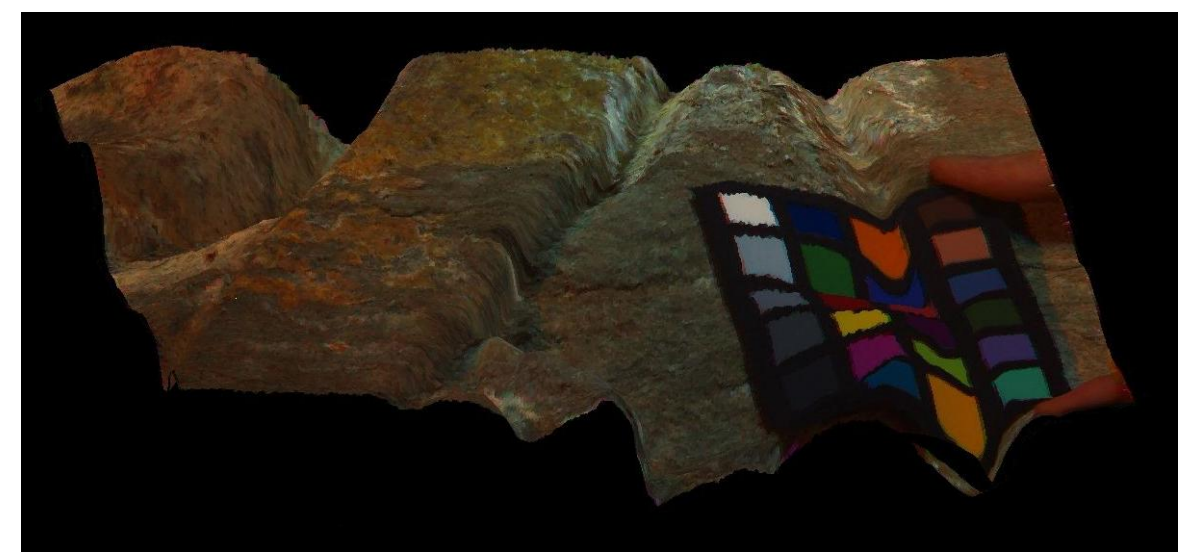

Figure 4: Multispectral data as texture on a 3D model. The mapping is incorrect where the Macbeth chart and fingers are shown because they are not part of the 3D scans. 


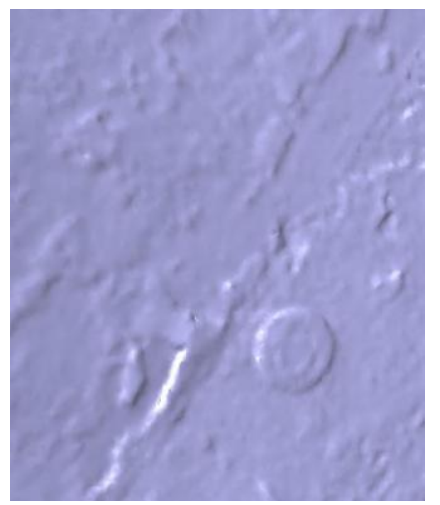

Figure 5: Detail of the 3D model of the wall painting in Rudesheim. The approximately $0.1 \mathrm{~mm}$ thick photogrametric target is observable.

The user selects corresponding points between the DEM and the hyperspectral data. These points are used to calculate the affine transform needed to project the multispectral cube onto the 3D data (Figure 3). Spectral data is then assigned to each pixel of the DEM and both datasets can be viewed as a single 3D object with hyperspectral accuracy texturing (Figure 4).

\section{RESULTS AND DISCUSSION}

The 3D scans captured during this study yielded satisfying results. Even with a coarse resolution, details are visible to better than the tenth of a mm (Figure 5).

To compare the 3D models of the sarcophagus that were acquired with a one year interval, we superimpose both models, using photogrammetric targets to guide this process. We then calculate the difference between the two models and display it as false colors texture over the first model. This describes how much material has eroded from the surface of the sarcophagus during the past year and where the loss is the greatest (Figure 6).

The registration between the $3 \mathrm{D}$ and multispectral data using our Matlab scripts is straightforward only when photogrametric targets are present in the field of view. This is the case of most of the multispectral data acquired with the contact-less spectral cameras, which has a large field of view. On the other hand, the fixed-lens camera, with its high spectral resolution and small field of view is most often used to monitor small sensitive zones. Since the photogrammetric targets are positioned in the periphery of the zones of interest, on less fragile surfaces, few acquisitions performed with the higher resolution multi-spectral camera picture a target. When the image does not include a target it is difficult to manually find corresponding points between the two types of data, 3D and color, even though this is currently our only option. Typically the 3D models of the wall paintings present few natural markers that can be used for registration, even though the color images are full of reference points such as the eye of a bird, intersections and corners (Figure 7). When dealing with the Trier data it is difficult to precisely assign a given position on the DEM to a particular pixel from the multispectral images. The surface roughness is relatively uniform and there are few salient and localized features. The smaller the field of view, the harder it is to find precise points of correspondence. In the absence of photogrametric targets to guide this process, the ensuing results are not very precise.

Though our registration technique can yield more precise results when the object is marked by targets, this practice is not adapted to cultural heritage applications where we try to reduce the physical disturbance to the object. This is particularly true when monitoring the aging of damaged surfaces. We do not want to disturb the already fragile areas by applying targets to it. Also, the monitoring takes place over several years during which the targets stay in place and create a visual disturbance on the surface. This is not a problem for a sarcophagus in a crypt that is not accessible to the public, but may not be permissible in a museum setting. In addition, the wear of the object can cause the photogrammetric targets to fall off.

Another limitation of our current registration procedure is due to the fact that our lab-developed Matlab scripts depend on a large number of external toolboxes. Though they enable us to quickly adapt and test multiple algorithms for our 


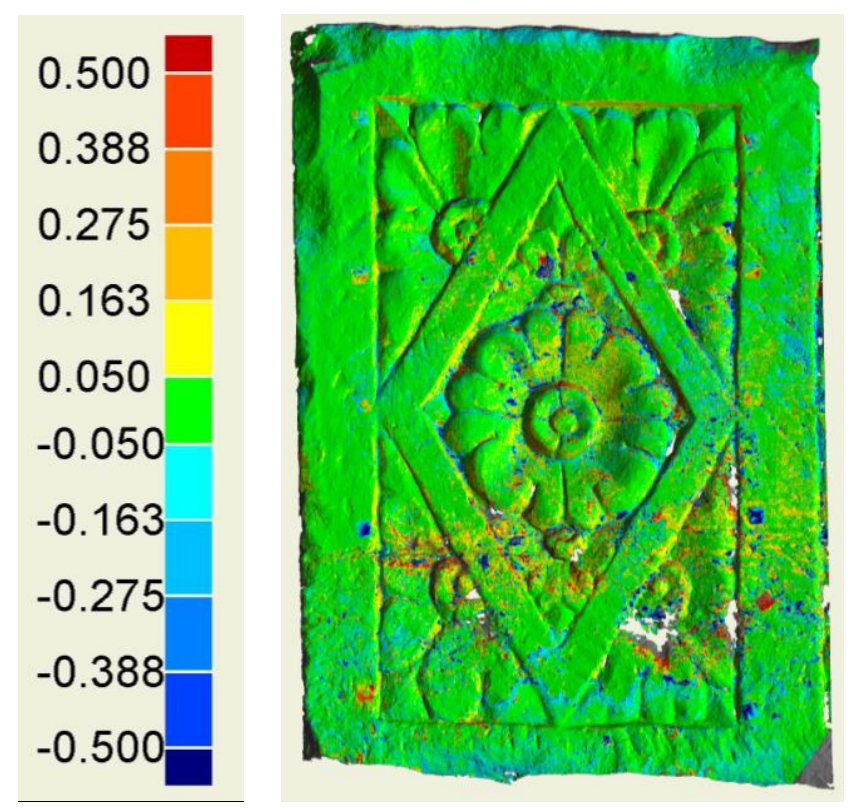

Figure 6: 3D model in false colors representing the erosion of the sandstone between December 2008 and 2009. Scale in millimeters. The areas in white represent zones for which there is no data. Such holes are represent areas that were not in the field of view of both acquisition cameras of the scanner and whose position could thus not be calculated.

application, these external libraries are poorly documented and it is difficult to accurately asses the precision of the ensuing registration.

Of our two multispectral cameras, the most precise must be in contact with the object during the acquisition. There are technical justifications for this: it ensures that the surface is in the focal plane of the lens and has the advantage of shutting out external light sources. However, when dealing with cultural heritage objects we favor non-contact systems, which is why we often use the other bulky and less precise system. A future spectral camera adapted to cultural heritage applications will have to address these issues, and to combine the strengths of both systems. We will also try to acquire better quality IR data.
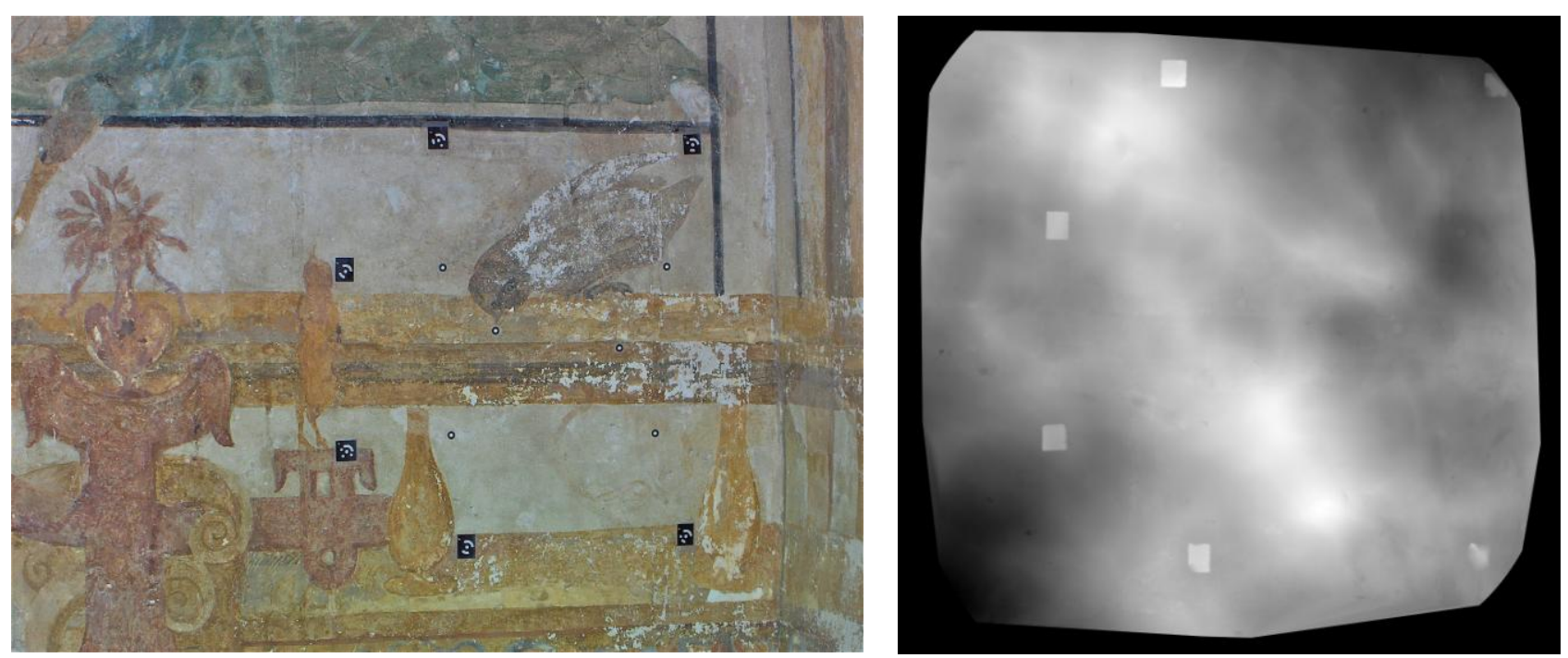

Figure 7: (a) A photo of an area of a wall-painting we are monitoring, with coded and un-coded photogrammetric targets. (b) The DEM of this zone. Discernable correspondence between the two images is faint. Only the targets can be easily located in both images. 


\section{CONCLUSION AND FUTURE WORK}

We presented the material used to acquire 3D data and multispectral images, as well as our current procedure to merge the two types of datasets. These are preliminary results of an ongoing project. Future work will include re-scanning the wall paintings in Rudesheim, using both 3D and multispectral acquisition techniques. We hope to precisely assign spectral changes to the $3 \mathrm{D}$ model and to observe correlations between the spectral and color flaking and the alteration of the surface morphology.

In the current setup, we can only aim at precise registration between the various datasets when targets are present in all images. However, multiplying the number of targets that we position on the surface of a fragile cultural heritage object is not recommended. Another way to perform precise transformations between the various data sets is to collect the geometry externally either mechanically, using a gantry, or optically. To address the registration process in a manner more appropriated to the context of cultural heritage we are currently orienting ourselves towards an external optical tracking of the exact position and orientation of the acquisition tools. We hope this will enable us to precisely register the various datasets with minimal disturbance to the object.

\section{ACKNOWLEDGEMENTS}

The authors would like to thank the financial support provided by the Conseil Régional de Bourgogne, France and i3mainz laboratory, Germany. Moreover, we would like to thank the Institute für Steinkonservierung, Germany which made it possible for us to acquire data in Trier and Rudesheim.

\section{REFERENCES}

[1] Heritage, A., "Imaging dynamic processes in conservation: online data acquisition and direct image annotation", 6th International Conference on Non-destructive Testing and Microanalysis for the Diagnostics and Conservation of the Cultural and Environmental Heritage, Rome, May 17-20. (1999).

[2] Levoy, M., "An interactive kiosk for the Tribune del David", http://graphics.stanford.edu/projects/mich/kiosk/kiosk.html, (2002).

[3] Koller, D. and Levoy, M., "Computer-aided reconstruction and new matches in the Forma Urbis Romae", Bullettino Della Commissione Archeologica Comunale di Roma, Supplementi 15, 103-125, (2006).

[4] Saunders, D. and Cupitt, J. "Image processing at the National Gallery: The VASARI Project", National Gallery Technical Bulletin, 14, 72-85 (1993).

[5] Pelagotti, A., Del Mastio, A., De Rosa, A. and Piva, A. "Multispectral imaging of paintings," IEEE Signal Processing Magazine, 25, 27-36, (2008).

[6] Rapantzikos, K. and Balas, C., "Hyperspectral imaging: potential in non-destructive analysis of palimpsests," IEEE International Conference on Image Processing, 2, 618-621, (2005).

[7] Blais, F., Taylor, J., Cournoyer, L., Picard, M., Borgeat, L., Godin, G., Beraldin, J., Rioux, M. and Lahanier, C. "Ultra High-Resolution 3D Laser Color Imaging of Paintings: The Mona Lisa by Leonardo Da Vinci", $7^{\text {th }}$ Int. Conf. on Lasers in the Conservation of Artworks: (Lacona VII), 435-440, (2007).

[8] Levoy, M., Pulli, K., Curless, B. Rusinkiewicz, S., Koller, D., Pereira, L., Ginzton, M., Anderson, S., Davis, J., Ginsberg, J., Shade, J. and Fulk, D., "The Digital Michelangelo Project: 3D Scanning of Large Statues," Proc. of ACM SIGGRAPH, 131-144, (2000).

[9] Boochs F, Huxhagen U, Kraus K. "Potential of high-precision measuring techniques for the monitoring of surfaces from heritage objects", Int. Workshop In-situ Monitoring of Monumental Surfaces, SWM08. Florence, Italy; (2008).

[10] Mansouri, A., Lathuiliere, A., Marzani, F. S., Voisin, Y. and Gouton, P. "Toward a 3D Multispectral Scanner: An Application to Multimedia," IEEE MultiMedia, 14(1), 40-47, (2007).

[11] Sanchez, M., Mansouri, A, Marzani, F. S., Gouton, P. "Spectral reflectance estimation from multispectral images using neural networks", Proc. of PSIP, (2005). 
[12] Böhler, W., Heinz, G., Bordas Vicent, M., Marbs, A. and Müller, H. "High Quality Scanning and Modeling of Monuments and Artifacts," Proc. FIG Working Week, (2004). 